\title{
Performance of the NCMRWF convection-
} permitting model during contrasting monsoon phases of the 2016 INCOMPASS field campaign

Article

Accepted Version

Jayakumar, A., Abel, S. J., Turner, A. G., Mohandas, S., Sethunadh, J., O'Sullivan, D., Mitra, A. K. and Rajagopal, E. N. (2020) Performance of the NCMRWF convection-permitting model during contrasting monsoon phases of the 2016 INCOMPASS field campaign. Quarterly Journal of the Royal Meteorological Society, 146 (731). pp. 2928-2948. ISSN 1477870X doi: https://doi.org/10.1002/qj.3689 Available at https://centaur.reading.ac.uk/84111/

It is advisable to refer to the publisher's version if you intend to cite from the work. See Guidance on citing.

To link to this article DOI: http://dx.doi.org/10.1002/qj.3689

Publisher: Royal Meteorological Society

All outputs in CentAUR are protected by Intellectual Property Rights law, including copyright law. Copyright and IPR is retained by the creators or other copyright holders. Terms and conditions for use of this material are defined in the End User Agreement. 


\section{www.reading.ac.uk/centaur}

\section{CentAUR}

Central Archive at the University of Reading

Reading's research outputs online 


\title{
Performance of the NCMRWF convection-permitting model during contrasting monsoon phases of 2016 INCOMPASS field campaign
}

\author{
A. Jayakumar ${ }^{*}$, Steven J. Abel ${ }^{2}$, Andrew G. Turner ${ }^{3,4}$, Saji Mohandas ${ }^{1}$, Jisesh Sethunadh ${ }^{1}$, \\ D.O'Sullivan ${ }^{2}$, A.K. Mitra ${ }^{1}$, E.N. Rajagopal ${ }^{1}$
}

\footnotetext{
${ }^{1}$ National Centre for Medium Range Weather Forecasting (NCMRWF), Ministry of Earth Sciences, A-50, Sector 62, Noida-201 309, INDIA

${ }^{2}$ Met Office, Exeter, Devon, EX1 3PB, UK

${ }^{3}$ Department of Meteorology, University of Reading, Reading, RG6 6BB, UK

${ }^{4}$ National Centre for Atmospheric Science, University of Reading, Reading, RG6 6BB, UK
}

This article has been accepted for publication and undergone full peer review but has not been through the copyediting, typesetting, pagination and proofreading process which may lead to differences between this version and the Version of Record. Please cite this article as doi: 10.1002/qj.3689 
*Corresponding author: A. Jayakumar

National Centre for Medium Range Weather Forecasting (NCMRWF), Ministry of Earth Sciences, A-50, Sector 62, NOIDA-201 309

Phone: +91-120-2419427

Email: (jkumar@ncmrwf.gov.in)

\section{Abstract}

This study uses INCOMPASS aircraft, radiosonde and satellite observations for verifying hydrometeors and associated state variables predicted by the regional model of the NCMRWF (NCUM-R) for contrasting phases of the 2016 monsoon. INCOMPASS flights B957 and B975 took place between Lucknow in northern India and Bhubaneswar near the east coast, and represent a contrast between dry pre-monsoon and active monsoon conditions, respectively. A moist profile above $4 \mathrm{~km}$ in Bhubaneswar measured on B957 showed a dry-air intrusion being eroded by mid-level clouds, whereas the Lucknow profile showed a drier, pre-monsoon profile. Aerosol extinction coefficient and cloud-top height measured using lidar showed an influx of 
continental aerosol, and intermittent multiple clouds below the aircraft in the mid-troposphere and boundary layer. Measurements from B975 match well with cyclonic wind patterns estimated from satellite observations and the convective tendency represented in radiosonde profiles. Extensive clouds were detected below $5 \mathrm{~km}$ during the active monsoon.

Two model formulations for cloud representation (prognostic cloud and prognostic condensate, PC2, and diagnostic schemes, Diag) are compared with observations during the campaign. Vertical structures of state variables from both schemes are generally in agreement along the flight tracks. Surface energy budget and cloud diagnoses indicate higher cloud cover

in Diag consistent with lower surface temperatures through reduced surface downwelling shortwave flux than in PC2, while the latent heat flux is found to be insensitive to cloud scheme chosen. In-cloud water content is larger in PC2 for lower cloud fraction, and the autoconversion process is faster with respect to Diag. Higher total condensed-water content in the model with respect to aircraft measurements and an enhanced light precipitation bias with respect to satellite data is common to both cloud schemes. Further work to improve the representation of clouds and precipitation for the tropical implementation of the model is clearly warranted.

Keywords: INCOMPASS, convection permitting, monsoon

\section{Introduction}

The monsoon supplies around $80 \%$ of India's annual rainfall between June and September. From the perspective of the India Meteorological Department (IMD), the monsoon onset is declared when the rain starts at Kerala, an Indian state on the south-west coast (Joseph et al., 2006). Recent studies by Fitzpatrick et al. (2016) and Mishra et al. (2018) give a new dimension to onset definition by considering the area of coherent regions where the presence of synoptic-scale 
controls is identified, and found it to be give a larger variability of the onset than previous measures. Parker et al. (2016) and Menon et al. 2018 showed that the progression of the monsoon onset in a north-westward direction can be explained in terms of the balance between both midlevel dry-air intrusions from the northwest and low-level monsoon flow. In addition to the local onset and demise of the monsoon, dry and wet conditions, representing active and suppressed phases of monsoon intraseasonal variability, have high socio-economic impacts, particularly in agriculture. Local monsoon onset and its variability plays a crucial role in determining the optimal planting date for rain-fed crops across the Indian subcontinent. Meanwhile, extended monsoon breaks such as the event of July 2002 can lead to significant reductions in crop yield and GDP (Gadgil and Gadgil, 2006).

Predicting extremes of monsoon precipitation is crucial for those General Circulation Models (GCMs) setup for forecasting; hence a deep understanding of the nature of such extremes in a model is essential. GCM representations of the Indian summer monsoon remain poor, with consistent dry biases of around 5 mm/day found over India in CMIP5 models (Sperber et al., 2013). These dry biases are coupled to a weakened monsoon circulation, a manifestation of the intimate connection between tropical convection and circulation. In addition to their weak mean monsoon rainfall, CMIP5 models feature a delayed onset (Levine et al., 2013). The seamless nature of the monsoon problem, with systematic errors developing rapidly over the first few days of a forecast (Martin et al., 2010) suggests that improvements made to the monsoon in NWP models will also result in improvements in climate simulations.

At smaller scales, tropical cloud processes and their feedbacks on the large-scale circulation are poorly understood and not well represented in models. Indeed, the coupling of clouds and circulation has been identified as a "Grand Challenge" by the World Climate Research Programme. Large-scale parametrization schemes for moist convection in GCMs often fare poorly in reproducing the observed structure of the cloud field. In contrast, the statistical properties of clouds tend to be better represented in higher resolution convection-permitting 
models that attempt to explicitly represent the convective processes (Golding et al., 2004). Hence, for the current study we focus on high resolution model simulations (grid length of 1.5 $\mathrm{km}$ ) to study the behaviour of contrasting monsoon conditions.

Model biases in the representation of clouds arise largely from an inadequate representation of hydrometeor distributions (Kumar et al., 2013). The NASA A-Train series of satellites are very useful products for providing information on cloud microphysical parameters and particularly of warm clouds, hitherto shielded from earlier satellite observations by layers of high cloud above them. For example, CloudSat Cloud Profiling Radars (CPRs), as part of the A-train series, provide estimates of warm rain globally. Some studies have discussed the deficiency of hydrometeor amounts in weather and climate simulations by using A-Train satellite products (e.g., Bodas-Salcedo, 2008), but the false-detection rate of hydrometeors is higher below $2 \mathrm{~km}$. Local to India, Jayakumar et al. (2017) recently used the regional model version of the National Centre for Medium Range Weather Forecasting (NCMRWF) Unified Model (hereafter NCUMR) for verifying the occurrence of hydrometeors during active periods of the monsoon using CloudSat satellite data. Verification of the short-range predictability of hydrometeor amounts and their distribution using CloudSat profiles is limited in accuracy, hence detailed measurement of cloud conditions from flight measurements, as will be used here, is one of the key tools for assessing model fidelity.

Observed information on the variability of vertical cloud microphysical characteristics under different rainfall conditions is essential for the improvement of cloud parametrizations in models. Profiles of liquid water content (LWC) affect the interaction of clouds with solar and infrared radiation, ultimately contributing towards the radiation budget. Information on hydrometeor profiles can improve our understanding of the cloud-microphysical processes acting to form and maintain cloud systems in the monsoon environment. Conversion processes, including the transition of LWC to rain water by the collision/coalescence of cloud droplets (autoconversion) and the collection of cloud droplets by falling raindrops (accretion), are vitally important in the 
formation of precipitation and its sub-grid variability. The Cloud Aerosol Interaction and Precipitation Enhancement Experiment (CAIPEEX) was one such attempt to look at the microphysics of pre-monsoon and monsoon clouds in India (eg. Prabha et al., 2011). That study determined that cloud droplets grows faster at lower levels in monsoon clouds, hence the onset of rain droplet growth is mostly confined just above cloud base, around $2.7 \mathrm{~km}$. Using CAIPEEX cloud probes, Maheshkumar et al. (2018) identified the varieties of hydrometeors and precipitation in the clouds present during the monsoon with respect to altitude of occurrence and temperature, their results indicating the presence of rain drops in LWC ranging from 0.5 to 2 $\mathrm{g} / \mathrm{m}^{3}$. However, none of these studies have discussed the detailed behaviour of hydrometeors in model simulations under contrasting monsoon conditions with respect to the detailed profiles possible in aircraft-observed values.

The UK Natural Environment Research Council (NERC) and India's Ministry of Earth Sciences (MoES) Monsoons Programme funded the INCOMPASS project (Interaction of Convective Organisation with Monsoon Precipitation, Atmosphere, Surface and Sea). INCOMPASS (described in more detail in Turner et al., 2019) consists of a field campaign during the 2016 monsoon season, together with associated modelling for case study analysis and forecasting. The unique observational platform used in INCOMPASS is the Facility for Airborne Atmospheric Measurement (FAAM) Atmospheric Research Aircraft, a modified BAe-146 jet hosting a range of in situ and remote-sensing instruments (see Section 2). During the INCOMPASS field campaign in 2016, the aircraft performed 22 sorties between June and July from airfields in Lucknow (Uttar Pradesh, northern India) and Bengaluru (Karnataka, southern peninsular India). A pair of flights from Lucknow, south-eastwards to Bhubaneswar and returning, during wet and dry periods of the 2016 monsoon will be the focus of study here.

One of the major differences in the tropical configuration of NCUM-R (Bush et al., 2019) from the earlier regional model configuration used in the mid-latitudes by the Met Office is the change from the Smith diagnostic cloud scheme ((known as Diag; Smith, 1990) to prognostic cloud and 
prognostic condensate (PC2; Wilson et al., 2008) scheme. The Diag scheme relies at the critical relative humidity value (enabling clouds to form above a threshold grid-box mean relative humidity value even if less than 100\%) and is modified by an empirically-adjusted cloud fraction scheme (EACF) and area cloud fraction scheme (Boutle and Morcrette, 2010) to compensate for an under-estimate in cloud cover. PC2 has memory in the grid square by the calculation of source and sink of prognostic fields (liquid fraction, ice fraction and mixed-phase fraction) and cloud cover, which is updated through advected fields (Wilson et al., 2008). Cloudiness in the PC2 scheme of the convection permitting model is represented by a combination of PC2 initialization near cloud base and PC2 pressure forcing throughout the cloud updraught (Morcrette, personal communication). More details of the cloud scheme in the convection permitting model is given in the section 4 of Bush et al., 2019. Bush et al.(2019) showed the benefit of PC2 against Diag over Singapore for predicting high impact rainfall events through changes effected in the boundary layer. INCOMPASS flight data provides an opportunity to quantify the impact of those cloud schemes over the South Asian monsoon domain.

Observations taken from INCOMPASS aircraft measurements during the 2016 monsoon allow for a detailed evaluation of the ability of the NCUM-R convection-permitting model at simulating cloud, temperature, moisture, precipitation and wind fields. In addition to the PC2 cloud scheme used in the Regional Atmosphere Tropical science configuration (RA1-T, Bush et al., 2019) of NCUM-R, the Diag scheme will also be considered here. The present study thus assesses the ability of NCUM-R at reproducing the cloud/precipitation distribution and associated thermodynamic and dynamic fluxes using two fundamentally different cloud parametrizations during the experimental periods and diagnoses the impact of choice of cloud scheme on simulation.

Section 2 provides information on the flight data and model used in this study, as well as a description of the experiments. Section 3 gives an overview of the case studies under contrasting monsoon conditions and Section 4 discusses the evaluation of different cloud-scale and 
thermodynamic processes and associated variables along the flight track. The final section discusses model-simulated cloud-liquid water content and its possible relationship with the representation of precipitation.

\section{Description of observations and model simulations}

Here we describe the flight data used in this study together with other supporting observations; in Section 2.2 we describe the model and experiments performed.

\subsection{Details of INCOMPASS data and processing methods}

\subsubsection{Flight information}

We have chosen INCOMPASS flights B957 and B975 based on the contrasting monsoon conditions between them (confirmed using an analysis of contemporaneous rainfall conditions and a monsoon index, detailed in Section 3), which operated on 12 June 2016 and 9 July 2016 respectively. Flight routes are illustrated in Figures $1 \mathrm{~b}$ and $\mathrm{c}$ as a red line overlaid on the accumulated rainfall, a merged precipitation product (IMD-NCMRWF; Mitra et al., 2013) from Integrated Multi-satellitE Retrievals for GPM (IMERG) and rain-gauge data, during the respective dates of the flights. Supplementary Figure1 gives the aforementioned observed accumulated rainfall for the same period since the traditional monsoon onset of 1 June. Both flights feature similar take-off times (0900LT for B957, 1000LT for B975) from Lucknow airport for a flight duration of 4 hours 30 minutes in each case. The flights pass over the eastern part of the monsoon core zone (MCZ), across parts of the Ganges basin and over forested regions towards the city of Bhubaneswar, located at the north-west coast of the Bay of Bengal. The outward portion of the flight initially profiled to high-level in order to characterize the atmospheric structure and cloud layers, followed by a high-level turn to remotely sense the 
underlying cloud and aerosol conditions using an on-board lidar. A second, deep atmospheric profile to low levels was then made with the aircraft close to Bhubaneswar. The return portion of the flight, as far as practical, was then flown at low levels within the boundary layer in order to make measurements of shallow clouds and examine land-atmosphere coupling.

\subsubsection{Aircraft instrumentation}

The FAAM BAe-146 research aircraft (http://www.faam.ac.uk) is fitted with a comprehensive suite of thermodynamic, radiometric, cloud physics and aerosol instrumentation. The instrumentation pertinent to this study include the following. Ambient air temperature was measured using a non-deiced Rosemount/Goodrich type-102 total air temperature sensor. Zonal, meridional and vertical wind components were derived from the five-port turbulence probe located on the aircraft radome (Peterson and Renfrew, 2009). Aircraft position and altitude data were measured with a GPS-aided inertial navigation system (Applanix POS AV 510). The GPS altitude data are subsequently corrected for the local geoid using the EGM96 worldwide 15minute binary geoid height dataset (Lemoine et al. 1997). Atmospheric water vapour content was measured using a WVSS-II near-infrared tunable diode laser absorption spectrometer fed from a modified Rosemount inlet (Vance et al. 2014). Cloud liquid water content (LWC) and total condensed water content (liquid cloud drop plus precipitation particles, TWC) were measured using a deep cone Nevzorov hot wire probe (Korolev et al. 2013), with the out-of-cloud baseline drift corrected using the method of Abel et al. (2014). The number concentration and sizing of cloud drops (2 to $50 \mu \mathrm{m}$ ) were measured using a Cloud Droplet Probe (CDP). Calculating the integral of the CDP size distribution provided an alternative measure of cloud LWC (figure not shown). All measurements along the flight track were analysed at a temporal resolution of $1 \mathrm{~Hz}$. Cloud-top height data were obtained using an on-board Leosphere ALS-450 elastic backscatter lidar, operating at $355 \mathrm{~nm}$ and pointing to nadir (Osborne et al. 2004). 


\subsubsection{Other observational and remote-sensing data}

In addition to the INCOMPASS flight data, we used hourly surface precipitation data from the Global Precipitation Measurement (GPM) mission of NASA's Integrated Multi-Satellite Retrievals (Huffman et al., 2014). Data from the European Centre for Medium-Range Weather Forecasts (ECMWF) ERA-Interim reanalysis (Dee et al., 2011) are utilized for generating pressure-level wind and temperature. Outgoing Longwave Radiation (OLR) is estimated from the geostationary satellite Kalpana-1's very high-resolution radiometer (VHRR) instrument over the Indian region (Mahakur et al., 2013).

To compare rainfall conditions between the two flights, the local onset of the monsoon is calculated based on the methodology discussed in Mishra et al. (2018). This new objective method, shown in Figure 1(a), defines the onset date based on the IMD-NCMRWF daily accumulated precipitation and is a more robust way of identifying the pre-monsoon and monsoon synoptic conditions in the local region covered by the flights. To confirm the contrasting monsoon conditions between the two cases studies, we also use the rainfall index of Rajeevan et al. (2010). Figure 1(d) shows the indices generated from the Rajeevan et al. (2010) method (black curve). We have chosen the two cases of 12 June 2016 and 9 July 2016 as they allow us to consider contrasting conditions as the monsoon seasonal cycle progresses, coinciding with the operation of two INCOMPASS flights B957 and B975.

We also use information from the Moderate Resolution Imaging Spectroradiometer (MODIS) (Stephens et al., 2002), a passive sensor on board the EOS Terra and Aqua satellites that measures radiances at 36 wavelengths with centre wavelengths ranging from the visible to long wave infrared and featuring a spatial resolution of $1 \mathrm{~km}$. The MODIS Level-2 cloud products used in this study give cloud-top properties, such as cloud-top pressure on a granule image from the measured radiances by employing infrared techniques such as $\mathrm{CO}_{2}$ slicing (Barnes et al. 1998). The cloud-top pressure indicates the location of the top of the radiating clouds, which are produced by infrared retrieval methods. The cold regions in these measurements show cumulus 
clouds or cumulonimbus clouds with cold tops, whereas warm regions correspond to low-level clouds.

\subsection{Details of the NCUM-R model}

The high-resolution NCMRWF version of the regional Unified Model (UM) (hereafter NCUM-R; Jayakumar et al., 2017) was used over a domain covering the eastern portion of the monsoon core zone with a horizontal grid length of $1.5 \mathrm{~km}$ over a domain of $1000 \mathrm{x} 1000$ grid boxes; in the vertical there are 80 levels with the model top at $38.5 \mathrm{~km}$ and 14 levels below $1 \mathrm{~km}$, the model domain is illustrated by a green box in Figure 1(b,c). The time step for NCUM-R is $60 \mathrm{~s}$.

We have used the tropical science configuration of UK Met Office Regional Atmospheric and Land model (RAL1-T, Bush et al., 2019). The initial and evolving 3-hourly lateral boundary conditions are derived from the operational 17 km grid-length NCUM global model (Rakhi et al., 2016). The details of the data assimilation employed in the parent NCUM global model are given in George et al. (2016). The model uses a dynamical core known as Even Newer Dynamics for General atmospheric modeling of environment (ENDGame; Wood et al., 2014) and a full suite of parameterized physical processes is included, such as: cloud microphysics based on a modified Wilson and Ballard scheme (Walters et al., 2017); radiation based on Edwards and Slingo (1996) and a four-layer land-surface scheme (Best et al., 2011); the only omission in NCUM-R is a convection scheme, since shallow, mid and deep convection is explicitly resolved. An orographic drag parametrization following Webster et al. (2003) is used as in the global version of the model but is effectively switched off in NCUM-R, since the effects of mean orography are sufficiently dominant at very high resolution. The sub-grid turbulence scheme used here is the blended scheme (Boutle et al., 2014), which dynamically combines the 1D boundary-layer (PBL) scheme of Lock et al. (2000) with a Smagorinsky scheme using a turbulent mixing factor of 0.5. 
Surface boundary conditions for the model are provided through ancillary files. Orography is derived from the NASA Shuttle Radar Topographic Mission (SRTM) 90 metre digital elevation map. Indian Space Research Organisation (ISRO) land use/land cover ( $\mathrm{Lu} / \mathrm{Lc}$ ) is used for defining tiles within the grid squares of the Joint UK Land Environment Simulator (JULES) land surface model (Best et al., 2011; Clark et al., 2011) and is derived from more recent observational data focused on India when compared to that of the International Geosphere and Biosphere Programme normally used in JULES.

\subsubsection{NCUM-R model experiments}

The experiments designed using the NCUM-R is based on two formulations of the cloud scheme. The first uses a prognostic cloud and prognostic condensate scheme, called PC2 (Wilson et al., 2008), which includes cloud liquid-water content, cloud ice-water content, and cloud fraction as prognostic variables. This is in contrast to the Diagnostic scheme (hereafter Diag), where water mixing ratio and cloud fractions are diagnosed from grid-box humidity. Diag uses the above mentioned Smith (1990) cloud scheme along with the area-cloud fraction (ACF, Boutle and Morcrette, 2010) and empirically adjusted cloud fraction (EACF) as described in Cusack (2002) in order to compensate for low-cloud fractions in the simulations.

The critical relative humidity (RHcrit) profile differs between the two cloud schemes. RHcrit is used to account for sub-grid variability in humidity, to enable clouds to form when the grid-box mean RH is below saturation (100\%), but the expectation is that saturation would exist somewhere within the grid square. In our PC2 run, an additional turbulent-kinetic-energy (TKE, Weverberg et al., 2016)-derived RHcrit is used, which is adapted to changes in the vertical (and horizontal) resolution. A fixed RHcrit profile is used in Diag, which is set at 0.96 at the surface, decreasing to 0.8 at $1 \mathrm{~km}$ and at all higher altitudes. 
The PC2 and Diag setups are compared in Table 1. The start date of each experiment is one day prior to the period of interest for the B957 and B975 cases, the integrations beginning from 00UTC 11 June and 00UTC 8 July respectively, each integrated for 75 hours. We use the t+24 hour forecast periods to avoid spin-up issues arising as the nested model adjusts to the driving global model forecast. To compare with flight data, state variables from the model are sampled every model time step (1 minute) to account for variability on a small local and temporal scale. For each $1 \mathrm{~Hz}$ in-situ observation from the aircraft, the model data is extracted in a $13.5 \mathrm{~km} \times$ $13.5 \mathrm{~km}$ box ( $9 \times 9$ grid points) centred on the nearest model grid to the aircraft position. The spread and median from the observations are calculated using the closest $60 \mathrm{1Hz}$ data points to the model time-step measured along the flight track.

The cloud top pressure from two experiments is used here for verification against MODIS observation. The estimated cloud top pressure is based on the cloud top height taken for the clouds above the 2.5 okta threshold, giving a reasonable comparison against satellite-retrieved cloud observations.

\section{Contrasting synoptic conditions during the two case study periods as observed in INCOMPASS}

In this section, we briefly review the synoptic situation for the case studies based on observations from the INCOMPASS campaign in addition to satellite observations.

The local onset of the Indian summer monsoon for 2016 is illustrated in Figure 1a and is defined as the first day after the minimum in daily cumulative anomaly of precipitation. This is calculated using India-averaged observed rainfall based on the new methods framed by Mishra et al. (2018). The B957 flight track overlaid on Figure 1b covers a transect from Lucknow towards Bhubaneswar, located on the north-west coast of the Bay of Bengal. This flight track covered regions featuring monsoon onset dates that varied between 29 May-8 June in Bhubaneswar to 818 June in Lucknow, which can be inferred from Figure 1(a). Hence, this flight (on 12 June) covers a route spanning the pre-monsoon to monsoon onset conditions. In contrast, the B975 
flight data will be used to examine atmospheric conditions once the monsoon has further advanced north and westwards across the Ganges basin (Figure 1c). The case studies for the aforementioned periods therefore represent pre-monsoon to onset (Figure 1b) and fully active monsoon conditions (Figure 1c).

On 12 June, a ridge situated over central India resulted in rain-free conditions in the western part of the monsoon core zone, whereas maximum lateral wind-shear conditions are found over the coastal Indo-Burmese rain belt (Figure 1b). The low-level wind structure for 9 July shows a jet axis passing from the central Arabian Sea eastward through peninsular India. The circulation associated with passage of a recent monsoon depression is evident, with maximum rainfall found over the north-west Indian mainland and north-east part of the Bay of Bengal (Figure 1c). A pair of rainfall maps shows the overall accumulation up to 12 June and 9 July respectively since the nominal start of the monsoon on 1 June (Figure S1). These indicate that the dry conditions in mid-June are followed by an active period in July, consistent with the climatological north-westward propagation of the monsoon seasonal cycle and associated with heavy precipitation over central and west coast regions of India.

Flight-measured winds and ambient temperature measured below 2000m altitude (from the low-level portion of the flights) are plotted over wind fields and air-temperature at 925hPa from ERA-Interim reanalysis (Figure 2). We have used ERA-Interim here since it is the data independent of the driving NCUM global model. Spatial verification of NCUM-R is discussed in Section 4. Apart from differences in the circulation pattern, a maximum of $\sim 10 \mathrm{~K}$ difference in temperature between these monsoon phases is evident in ERA-interim. Spatial variations in the ERA-Interim temperature field (Figure 2a) at different locations across the flight transect follow the expected nature of the monsoon with changes in the local onset days as shown in Figure 1a. The reanalysis is found to be more than $8 \mathrm{~K}$ warmer than aircraft temperature observations between 7:15UTC and 7:30 UTC. This mismatch is possibly is due to the aircraft's profile descent from $2 \mathrm{~km}$ to $500 \mathrm{~m}$ (Figure 6e) between this period, and the colder temperature measurement of the aircraft at 7:15 in Figure 2a is at higher altitude of $\sim 1000 \mathrm{~m}$ than the that of 
the reanalysis data at $925 \mathrm{hPa}$. Overall, the reanalysis low-level temperature and wind circulation is broadly consistent with INCOMPASS flight measurements.

State variables and total water content from the initial profile in the northern portion following take off from Lucknow (red) and the profile over Bhubaneswar in the southern sector (black) for both cases are depicted in Figure 3. The aircraft profiles from flight B957 sampled areas that exhibited both pre-monsoon (Lucknow) and onset (Bhubaneswar) conditions. Dew point temperatures are closer to ambient temperature above $4 \mathrm{~km}$ in the Bhubaneswar profile than those in the Lucknow profile (Figure 3a). In addition, mid-level clouds were detected in the downward-pointing lidar observations (Figure 5) during the onward flight to Bhubaneswar. This would imply that as the monsoon progresses, convection transports the low-level moisture to mid-levels and reduces the drier conditions that were prevalent prior to the onset. The moisture profile above $4 \mathrm{~km}$ over Bhubaneswar could be due to the dry-air intrusion being eroded by midlevel clouds (Figure 3a), which is a notable feature of the monsoon onset as discussed in Parker et al. (2016) and Menon et al. (2018). Enhanced boundary layer turbulence (50m to $2 \mathrm{~km}$ ) was observed in the Bhubaneswar onset profile when compared to the pre-monsoon profile of Lucknow from the vertical velocity profile shown in Figure 3c, whereas no significant cloud water is observed in both profiles (Figure 3d). There is no radiosonde sounding available during those flight periods with which to generate a comparison profile.

In the case of flight B975, both profiles shown in the lower panels of Figure 3 indicate the convective atmospheric conditions associated with the active monsoon phase. Evidence of larger mid-level cloud water contents are found at 4-6 km altitude (2-4 km) in the Bhubaneswar (Lucknow) profile (Figure 3h). A sounding from the ground for the B975 period for both aforementioned stations is depicted by tephigrams as in Figure 4, which give a comparison profile for the B975 flight sounding observations depicted in Figure 3e. In agreement with flight observations, the dew point temperature $\left(T_{\mathrm{d}}\right)$ is much closer to environmental temperature $(T)$ even above $600 \mathrm{hPa}$, indicating the enhanced relative humidity over these locations (Figure 4). 
The details of verification of model (dashed lines) against observed profiles will be discussed in the next section.

Figure 5 shows the aerosol extinction coefficient (shaded, $\mathrm{Mm}^{-1}$ ) and cloud-top height derived from the aircraft lidar for flights B957 and B975. Red, green and blue circles indicate the $1^{\text {st }}, 2^{\text {nd }}$ and $3^{\text {rd }}$ cloud top heights detected below the aircraft respectively. A detailed study of the aerosol composition and its vertical distribution measured from these flights is discussed in Brooks et al (2019). During the pre-monsoon flight B957, more polluted continental air was observed overlying the relatively dry air in the eastern sector of the monsoon core zone. The existence of intermittent multiple clouds was detected in the 5-7 km range and also below $1 \mathrm{~km}$.

For flight B975 (active case), extensive clouds are generally detected below $5 \mathrm{~km}$. It is likely that the cloud observed here was thick enough to completely attenuate the lidar signal and so only information on the uppermost cloud tops beneath the aircraft are detected. It should be noted that during this flight the lidar laser power was lower than usual, resulting in lower aerosol detection limits and signal-to-noise ratio than for B957. A higher frequency of mid-level stratiform clouds is observed during the active monsoon conditions, which are in general agreement with an earlier study by Prabha et al. (2011) using CAIPEEX flights observations in 2009. During the low-level run between 6:30 and 8:15 UTC, the aircraft flew through cloud as indicated by the non-zero Nevzerov LWC measurement values shown in Figure 11b.

\section{Evaluation of NCUM-R and its sensitivity to cloud parametrization}

Here we assess the performance of the NCUM-R for case study experiments performed for the two flights and examine the sensitivity of the cloud and hydrometeor behaviour to the cloud parametrization employed.

\subsection{Comparison of wind, water vapour and temperature fields}


This section includes the comparison of $\mathrm{t}+24$-hour forecasts of primary fields from PC2 and Diag experiments with aircraft data and radiosonde observations associated with the INCOMPASS campaign. Spread in the observations and model is represented by plus and minus one standard deviation from the mean, and is based on the algorithm discussed in section 2.21.

The turbulence probe measurements for zonal and meridional components of wind for both flights through the eastern portion of the MCZ are plotted as an altitude-time graph in Figure 6. For the pre-monsoon flight B957 (Figure 6a) only a westerly component of zonal wind is found during the low-elevation portion of the flight, which is a part of the circulation around the ridges over north-west India; this observation is also consistent with the lack of an established monsoon trough so far north at this time, which would tend to bring south-easterly winds inland from the head of the Bay of Bengal. There are typically only marginal differences in the zonal wind predicted between the two model configurations. However, there is a significant difference of $\sim 10 \mathrm{~m} / \mathrm{s}$ in the mid-levels (4000m) at 8:45 UTC and at the $7000 \mathrm{~m}$ level after 6:00 UTC.

The B975 active monsoon flight covers the location of both the easterly half of the monsoon depression and the westerly component of the low-level jet over the Indian peninsula between 6:30 UTC and 8:15 UTC. Unlike for pre-monsoon flight B957, the elongated cyclonic circulation as a part of the monsoon trough is now reflected in the easterly wind component of Figure $6 \mathrm{~g}$ between 4:30 and 6:30 UTC. In contrast, a mid-level dry air intrusion ( 400hPa), common during the onset progression of the monsoon (Parker et al., 2016), provides a westerly component during the time of the B957 flight, as measured during the travel period of 5:45 UTC to 7:15 UTC (Figure 6f). The strength of this westerly is considerably enhanced in the northern sector in the proximity of Lucknow compared to the southern side near Bhubaneswar, a difference that is clearly exhibited in both the model and FAAM probe measurements. The model capability at forecasting location-specific features of the low-level flow demonstrates 
good skill even though the zonal wind is generally found to be stronger than found in the flight observations.

The model temperature field at low levels is generally in agreement with observational values for the active monsoon case of B975 (Figure 6h), whereas for the pre-monsoon case, the forecast low levels are found to be warmer (Figure 6c). Similarly, the differences in mixing ratio of water vapour are found to be larger in the pre-monsoon case and sensitivity of these parameters to the choice of PC2 and Diag cloud scheme is found to be maximum in the 7:15 UTC to 8:30 UTC period (Figure 6d). These two state variables of temperature and mixing ratio cover a wide range of values across the flight levels; hence a box and whisker diagram for different altitude bands of $1000 \mathrm{~m}$ depth extending from $1000 \mathrm{~m}$ to $8000 \mathrm{~m}$ is presented in Figure 7 to compare better for forecast and observed values. The diagram shows the relative bias (model minus FAAM observations) of temperature and specific humidity for the pre-monsoon (Figure 7a, b) and active (Figure 7c, d) case, where the box spans the interquartile range (25\% to $75 \%$ percentiles), the median is marked by a vertical line inside the box and the outlier (black diamond) are data points lying outside the upper and lower whisker or extremes. A difference between the maximum temperatures at low levels (1000m altitude band) of $\sim 3.8 \mathrm{~K}$ is evident in the plots, which is more prominent in PC2 than Diag (Figure 7a). The warming tendency in the model is reduced as altitude increase, and the bias reverses from $6000 \mathrm{~m}$ to $7000 \mathrm{~m}$. A dry bias is evident at lower atmospheric levels in both simulations (Figure 7b); except at 4000m the moisture bias at other altitude bands is insensitive to the choice of cloud scheme.

For the active case, biases in temperature (Figure 7c) and water vapour contents (Figure 7d) are found to be relatively smaller in both model configurations, whereas for the pre-monsoon case, the model lower layers are systematically warmer and drier than observations (Figure 7a,b). To gain further insight into the sensitivity of the surface temperature towards the cloud scheme the surface heat flux budget is analysed for the pre-monsoon and monsoon cases in PC2 and Diag simulations and are plotted in Figure 8(a, b) and Figure 8(e, f) respectively. 
The surface energy balance equation is given by

$\mathrm{Q}^{*}=\mathrm{GH}+\mathrm{LH}+\mathrm{SH}+\mathrm{Res}$

where GH is the soil heat flux at the surface, $\mathrm{Q}^{*}$ is the net radiation, $\mathrm{LH}$ is the latent heat flux, $\mathrm{SH}$ is the sensible heat flux and Res is the residual term (all in units of $\mathrm{Wm}^{-2}$ ). A higher loss of energy from the surface by LH than $\mathrm{SH}$ is found for the monsoon (and vice-versa is found for pre-monsoon case) is evident in Figure 8. An enhanced value of $\sim 100 \mathrm{Wm}^{-2}$ is simulated in the net radiation term of PC2 in comparison to Diag for both cases, and results in the higher surface temperature. A map of the downwelling short wave flux map is depicted in the lower panels of Figure 8). It can be inferred that the increased cloud cover in Diag, which results in lower surface temperatures when compared to PC2 through reduced surface downwelling shortwave flux. The latent heat flux is similar in both simulations of the pre-monsoon case, where the model has a dry bias which found to be insensitive to the two model simulations.

Similarly, the time mean of the $t+30$ to $t+33$ hour forecasts for air temperature and low-level winds from NCUM-R for PC2 and Diag are illustrated in Supplementary Figure 2. Here morning hours (4.30 UTC) observation is removed to be consistent with observation measured during return flight to Lucknow and to avoid the diurnal variation in the parameters considered. Patterns of variability for the aforementioned variables from both experiments during the active monsoon period are broadly similar to ERA-Interim. The model tends to be warmer than the reanalysis and aircraft observations for the pre-monsoon (not shown). Overall, reanalysis and NCUM-R forecasts are broadly consistent with the INCOMPASS flight measurements.

The meridional component of the model wind shows larger deviations from observations at all altitude levels with respect to zonal components (Figure 6g). The turning of meridional wind from southerly to northerly in the lower levels is better predicted in Diag compared to PC2, although the timing of the peak northerly component is earlier than observed between 7:30 UTC and 8:15 UTC. 
Figures 9a,b and 9c,d compare the profile of vertical velocities taken from the flight departing from Lucknow and the descent over Bhubaneswar from B957 for the period 7:00 to 7:15 UTC and B975 during 6:15 to 6:30 UTC respectively. The mean observed profile (black solid line) and spread is depicted in this diagram; corresponding model simulations from PC2 (red solid line) and Diag (green solid line) NCUM-R experiments are also shown here.

Pre-monsoon conditions show downdrafts often throughout the flight during the low-level sector $(0-2500 \mathrm{~m})$ and in the upper level (5000-6000m) in addition to the descending motion at altitudes between 3500m and 4500m. The influx of transported aerosols carried by westerly and northwesterly winds descends from the upper levels. PC2 shows enhanced ascent/updrafts that would act to transport boundary layer moisture upwards to mid-levels (Figure 9a), that might explain the enhanced moisture when compared to Diag in Fig $7 \mathrm{~b}$ ( $4.5 \mathrm{~km}$ altitude). An underestimate of model vertical velocity in the surface layer in Figure 9b may be due to inefficient landatmosphere coupled processes in the model in response to warm biases in low-level temperature. More details of the NCUM-R land-atmosphere coupling during the campaign period is discussed in the recent work of Barton et al (2019). For the active monsoon conditions (Figure 9c), the profile over the continental location (Lucknow) from the model is found to contain stronger updrafts; specifically Diag gives a maximum updraft in the mid-levels, which is missing in the PC2 simulations. Meanwhile for the marine profile, both experiments are found to be incapable in simulating the variations of vertical velocity in the column (Figure 9d). Profiles of temperature and dew-point from PC2 (dash) and Diag (dot-dash) against sonde observations over both these location is given figure 4. For the Lucknow, both simulations showed a more convective condition than observation, though model shows a better comparison over Bhubaneswar. The low-level variability in model vertical velocity is found to be is lower in sea points than gridboxes away from the coast (Supplementary Figure 3), as Bhubaneswar is close to the coast, the smaller vertical velocities variability is shown in model as compared to the observations. In general, the model underestimates the variability of the vertical velocity of Bhubaneswar profile and overestimate Lucknow profile as illustrated in Fig.9d and Fig.9a respectively. 


\subsection{Cloud and precipitation simulation}

OLR estimated from the Kalpana-I IR images and the model-simulated OLR averaged for the period of 3-9 UTC on each day is presented in Figure 10. For both cases, OLR simulations from the two schemes generally agree with the Kalpana satellite retrievals, though there are differences found over some locations (lower panels of Figure 10). Pockets of colder cloud tops are found in the Diag experiment compared to PC2, suggesting deeper clouds in Diag with respect to both PC2 and Kalpana observations. In regions of heavier precipitation, Diag has higher convective cloud tops than PC2. Meanwhile, the northern sector of the monsoon core zone (along flight tracks in the vicinity of Lucknow) is found to feature lower OLR values, which indicate shorter-lived and shallower cloud in PC2 against Diag.

Figure 10 (upper panels) shows the accumulated rainfall amounts from the two model experiments compared with GPM rainfall. Stronger heavy convective cells are located in the southwestern sector of the domain we selected for B975, whereas the rain-free regions observed in the eastern sector are largely covered by light amounts of model precipitation. Further histogram analysis for the PC2 and Diag simulations against GPM satellite rainfall estimates shows that PC2 is producing a lot more light rain than Diag (Supplementary Figure 4).

Cloud top pressure, which is calculated based on 2.5okta cloud height, is simulated from the two experiments in order for verification against MODIS observations at 5:35 UTC on 9 July. MODIS has an advantage of detecting geometrically thin, low-level cloud (Chan and Comiso, 2011), hence used here for measuring clouds exist in the altitudes lower than $1200 \mathrm{~m}$ The cloud top pressure in the PC2 simulation shows reduced spatial coverage with respect to that in Diag (Figure 11), possibly due to the shallow clouds drizzling out at each model time step in the PC2 simulation. While the observed low level cloud patches surrounding coordinates $25^{\circ} \mathrm{N}, 85^{\circ} \mathrm{E}$ (south-east sector of the Figure) is captured reasonably well in Diag, it is not very evident in PC2 
run. This cloud-to-rain transformation is evident in the horizontal distribution of cloud fraction, autoconversion and accretion rate calculated for the B975 case period from both PC2 and Diag experiments (Figure 13). Further details on model sensitivity in the distribution of cloud-water content to the choice of cloud scheme will be discussed in the next section.

\subsection{Comparison of prognostic and diagnostic mixing ratio}

The liquid phase dominates in the active monsoon cloud of B975 around 6:20 UTC and 8:15 UTC. At an altitude of around 4-6 km, the maximum value from the Nevzorov measurements is above $0.25 \mathrm{gm}^{-3}$ (Figure 12b). Reasonable agreement between the two Nevzorov sensors and the CDP indicates a liquid-dominated cloud at this level (not shown). The Diag simulation shows enhanced LWC compared to PC2 during this period. From 6:30 to 8:10 UTC, the flight is passing through levels less than 1200m above ground, which is below the height of the freezing level, and all of the TWC is in the liquid state. In the model simulation also, LWC only represents cloud water, while TWC indicates the total rain and cloud water. The higher readings on the Nevzorov TWC sensor (Figure 12a) as compared to LWC sensor (Figure 12b) indicate the presence of precipitation sized particle on the low-level run. LWCs generated from Diag are estimated to be higher than the observations and PC2 at these levels. The maximum LWC from Nevzorov in the lower layers is approximately $\sim 0.05 \mathrm{gm}^{-3}$, whereas it exceeds $0.15 \mathrm{gm}^{-3}$ in Diag. In the case of TWC in the simulations, the maximum value of TWC from PC2 exceeds $0.7 \mathrm{gm}^{-3}$. The TWC sensor observations are relatively lower than the model simulations except for 8:10 UTC at $\sim 2000 \mathrm{~m}$ altitude. The effect of convective plumes detraining both vapour and condensate from shallow cloud gives rise to a higher cloud cover, which affects the shortwave radiation budget in the lower levels. This fractional cloud cover is greater in the Diag simulation, supported by EACF and ACF being used, which results in the reduction of solar radiation (Figure 8), and is reflected in surface temperature cooling. Once the flight ascends to an elevation of 4000-5000m, again large amounts of LWC are recorded in the instrument (around 
8:57 UTC), where the model values are underestimated. Stratiform types of cloud present near the mid-level atmosphere over the northern sector of the flight track may have caused this enhanced LWC. This can also be seen as the greenish patch $\left(\sim 240 \mathrm{Wm}^{-2}\right)$ in the Kalpana OLR at the northernmost location of the track (Figure 10). For the pre-monsoon case, there is no significant cloud or precipitation pattern observed along the low-elevation flight track. Hence both model and observed LWC amount is totally absent at this level (not shown).

Spatial map of cloud fraction, autoconversion, accretion, and evaporation rate obtained by averaging the levels from 1000m to 2500m of lower atmosphere from PC2 and Diag are shown in Figure 13. Diag gives a larger cloud cover area with higher magnitude in compared to PC2 (Figure 13a, b), whereas LWC integrated for the aforementioned atmospheric levels is showing an insignificant difference between the two cloud schemes (Fig. 13b, g). Rain formation via autoconversion in the PC2 experiment is showing higher areal spread than in Diag in those model gridpoints through which the flight transect passes at low levels. The prediction of higher values of the autoconversion/accretion process occurs at a larger number of grid points in PC2 than in Diag. Significant difference in the evaporation rate (Figure 13 c and Figure 13f) between both experiments are not seen over the aforementioned locations.

The autoconversion formulation is the same for the same amount of in-cloud liquid water in both simulations, however, with smaller cloud fractions in PC2 and the same LWC, then the in-cloud water content would be larger in PC2 and in consequence the autoconversion process would be faster. The PC2 simulation generates cloud liquid water while the Smith scheme in Diag diagnoses it. This water then produces drizzle, which is a lot more in the PC2 run because there is simply higher in-cloud water to drizzle away

\section{Discussion and Conclusions}

This article is protected by copyright. All rights reserved. 
Atmospheric Research Aircraft measurements from the 2016 INCOMPASS field campaign were used here for verifying NCUM-R simulations using two fundamentally different cloud parameterizations schemes. We have identified cases from the pre-monsoon and active phases of the 2016 monsoon as determined by rainfall (Rajeevan et al. 2010) in addition to a local-onset method of Mishra et al. (2018). NCUM-R simulations for those cases are evaluated with data from FAAM research flights B957 and B975 respectively, both of which operated between Lucknow and Bhubaneswar in northern India. The aforementioned cases are ideal representations of opposite extremes of monsoon regimes with respect to both precipitation and circulation patterns. Model-forecast horizontal wind fields for these periods are generally in agreement with observed values from on-board wind probes. An elongated cyclonic circulation as a part of the monsoon trough in the model for the active case is observed in both low and high elevation B975 flight tracks. Meanwhile, a mid-level westerly dry intrusion is clearly observed during the B957 period; this dry intrusion could be remnants of the feature present during the climatological monsoon onset (Parker et al., 2016), or also observed during breaks such as the July 2002 event (Bhat, 2006).

In general, the atmospheric temperature and water vapour content agree with the flight measurements. Two cloud microphysics schemes were tested for each forecast experiment. The presence of extensive shallow clouds in the Diag simulation compared to PC2 resulted in cooling at lower levels. Water vapour contents below $2000 \mathrm{~m}$ show a wet bias in moisture at the lower level for the monsoon case; where as a dry bias is evident in the pre-monsoon case, which is insensitive to the choice of cloud scheme. This is possibly linked to an elevated cloud base and the lifting of water vapour content to mid levels (Figure 7) determined from the vertical velocity profiles (Figure 9). Specifically, for the pre-monsoon period, the warm pockets over the IndoGangetic plain tend to show a dry regime in specific humidity. During this period, due to the extensive warm surface layer, model shows a higher value of vertical velocity over continental grids (Lucknow profile), whereas vertical velocity is under-estimated in coastal regions (Bhubaneswar) in both experiments. For the active case, the model-simulated light rainfall bias 
prominent in PC2 is possibly due to the accelerated cloud water-to-rain water conversion, whereas the extensive shallow cloud in the Diag simulation resulted in a low rainfall bias and results in a colder surface layer.

NCUM-R is shown to be a good tool for studying different monsoon conditions without losing local fine-scale features and is in agreement with the measurements obtained from the FAAM aircraft, the model tends to have a deficient (excess) moisture bias for the pre-monsoon (monsoon) regimes. TWC analysis inferred a higher frequency of light precipitation/drizzle for PC2 than in Diag over otherwise rain-free regions found in the GPM satellite-retrieval data. Although the radiative diagnostics in PC2 are reasonable (Figure 8), the shallow convective cloud almost completely drizzles away at each time step. Since the radiation scheme is called in parallel with the large-scale precipitation scheme, the radiative effect of these clouds in PC2 is seen before the drizzle process acts. Surface energy budget analysis and cloud diagnostics from the current study concluded that the increased cloud cover in Diag resulted in lower surface temperatures than PC2 through lower surface downwelling shortwave flux, where the latent heat flux is found to be found to be insensitive to the two model simulations irrespective of the model dry bias.

The parametrization of autoconversion of cloud water to rain in the large-scale scheme is very efficient, but more importantly, it can act without a time delay and can quickly create larger-size drizzle and rain droplets. Though the LWC from the NCUM-R is comparative in amount to the aircraft, major biases exist in the TWC, which points to the model microphysics rather than the changes in cloud scheme as the cause. The current model representation of the rain drop-size distribution is based on aircraft field experiments over Atlantic and Pacific regions as discussed in Abel and Boutle (2012); this could possibly contribute to biases in precipitation for the monsoon environment, hence the INCOMPASS flight and wider field experiments provide an opportunity for developing the model microphysics scheme to better describe cloud process in the Indian region. In future work, precipitation estimates from quality controlled 
Doppler weather radar data is preferred as a replacement for GPM in order to better assess the spatial and temporal characteristics of model rainfall at $1.5 \mathrm{~km}$ resolution.

Bush et al. (2019) mentioned the advantage of the PC2 cloud scheme over Diag for the Singapore domain, a location where local weather systems are highly modulated by squall lines, for predicting high impact rainfall events; however, the conclusion of our study is that PC2 gives an overestimation at lower precipitation thresholds over the South Asian monsoon domain based on the aforementioned case studies. In short, surface temperature is highly sensitive to changes in cloudiness, and in the cloud-to-rain transformation, through the faster removal of in-cloud water content, which is reflected in the higher areal spread for precipitation rates at lower thresholds (drizzle) in the PC2 with respect to Diag simulation of NCUM-R (Figure 10 and Supplementary Fig.4). There are biases seen in few variables (eg. moisture bias) which are not sensitive to the cloud scheme, and are expected to improve in the upgraded version of the model.

Results from this study provide an input for the improvement of the tropical settings of the NCUM-R and versions of the model employed at the UK Met Office RAL1-T focused on better monsoon forecast and for further development of the current cloud-prognostic scheme, which is relatively new. Flight tracks used in the current study were not able to pass through any heavy convective cell, which limits our study to regions of light precipitation only. The current work is focused on the observations from two aircraft data sets based on contrasting synoptic situations; Sandeep et al. (2019) will provide a complete comparison of NCUM-R performance with all flights from the northern portion of the INCOMPASS field campaign.

\section{Acknowledgements}

We have highly benefited from scientific discussions with Charmaine Franklin, BOM, Australia and Cyril Morcrette, UK Met Office. This work is funded by the INCOMPASS project, a joint initiative between the UK Natural Environment Research Council (NERC) and the Indian Ministry of Earth Sciences (MoES). AG Turner was funded under NERC grant numbers NE/L01386X/1 and NE/P003117/1. 


\section{References}

Abel, S. J., Cotton, R. J., Barrett, P. A., and Vance, A. K., (2014) A comparison of ice water content measurement techniques on the FAAM BAe-146 aircraft, Atmos. Meas. Tech., 7, pp. 3007-3022, doi:10.5194/amt-7-3007-2014.

Barton, E. J., Christopher M. Taylor, Douglas J. Parker, Andrew G. Turner, Danijel Belusic, Steven J. Böing, Jennifer K. Brooke, R. Chawn Harlow, Phil. P. Harris, Kieran Hunt, A. Jayakumar and Ashis S. Mitra, (2019) A Case Study of Land-Atmosphere Coupling During Monsoon Onset in Northern India, Q. J. R. Meteorol. Soc. published online. DOI: 10.1002/qj.3538

Barnes, W. L., Pagano, T. S. and Salomonson V. V, "Prelaunch characteristics of the Moderate Resolution Imaging Spectroradiometer (MODIS) on EOS-AM1,” IEEE Trans. Geosci. Remote Sens., vol. 36, no. 4, pp. 1088-1100, Jul. 1998.

Best MJ, et al. (2011) The Joint UK Land Environment Simulator (JULES), model description Part 1: Energy and water fluxes. Geoscientific Model Development 4(3): 677-699

Bhat, G. S. (2006) The Indian drought of 2002 - a sub-seasonal phenomenon? Q. J. R. Meteorol. Soc. 132, 2583-2602.

Bodas-Salcedo, A., M. J. W ebb, M. E. Brooks, M. A. Ringer, K. D. W illiam, S. F. Milton, and D. R. Wilson (2008), Evaluating cloud systems in the Met Office global forecast model using simulated CloudSat radar reflectivities, J. Geophys. Res., 113, D00A13, doi:10.1029/2007JD009620. 
Boutle, I. A., Eyre, J. E. J., and Lock, A. P., (2014), Seamless stratocumulus simulation across the turbulent gray zone. Mon. Wea. Rev., 142, 1655-1668, doi:10.1175/MWR-D-13-00229.1.

Boutle, I. A. and Morcrette, C. J., (2010), Parametrization of area cloud fraction, Atmos. Res. Lett., 11, 283-289, https://doi.org/doi: 10.1002/asl.293.

Brooks, J., Allan, J. D., Williams, P. I., Liu, D., Fox, C., Haywood, J., Langridge, J. M., Highwood, E. J., Kompalli, S. K., O'Sullivan, D., Babu, S. S., Satheesh, S. K., Turner, A. G., and Coe, H., (2019): Vertical and horizontal distribution of sub-micron aerosol chemical composition and physical characteristics across Northern India, during the pre-monsoon and monsoon seasons, Atmos. Chem. Phys. 19: 5615-5634. DOI: 10.5194/acp-19-5615-5634.

Bush et al., 2019, The first Met Office Unified Model/JULES Regional Atmosphere and Land configuration, RAL1, https://doi.org/10.5194/gmd-2019-130.

Cusack, 2002: The Empirically Adjusted Cloud Fraction modification to the cloud scheme, Internal report, UK Met Office.

Dee, D. P., et al. (2011), The ERA-Interim reanalysis: Configuration and performance of the data assimilation system, Q. J. R. Meteorol. Soc., 137, 553-597, doi:10.1002/qj.828

Edwards, J. M., \& Slingo, A. (1996). Studies with a flexible new radiation code. I: Choosing a configuration for a large-scale model. Quarterly Journal of the Royal Meteorological Society, 122, 689-719.

Fitzpatrick, R. G. J., D. J. Parker, and P. D. Willets (2016), Assessing the level of spatial homogeneity of the agronomic Indian monsoon onset Geophys. Res. Lett., 43, 11867-11874, doi:10.1002/2016GL070711 
George, J. P., S. Indira Rani, A. Jayakumar, S. Mohandas, S. Mallick, A. Lodh, R. Rakhi, M. N. R. Sreevathsa, and E. N. Rajagopal (2016), NCUM Data Assimilation System, NCMRWF Technical Report, NMRF/TR/01/2016.

Golding, B., Mylne, K. Clark, P. (2004) The history and future of numerical weather prediction in the Met Office. Weather, 59: 11.

Gadgil, Sulochana and Siddhartha Gadgil (2006) The Indian Monsoon, GDP and Agriculture, Economic and Political Weekly, XLI, 4887-4895

Jayakumar, A., Sethunadh, J., Rakhi, R., Arulalan, T., Mohandas, S., Iyengar, G. R., \& Rajagopal, E. N. (2017). Behavior of predicted convective clouds and precipitation in the high-resolution Unified Model over the Indian summer monsoon region. Earth and Space Science, 4, 303-313. https://doi.org/10.1002/2016EA000242

Joseph, P. V., K. P. Sooraj, and C. K. Rajan (2006), The summer monsoon onset process over South Asia and an objective method for the date of monsoon onset over Kerala, Int. J. Climatol., 26, 1871-1893

Korolev, A., J. W. Strapp, and G. A. Isaac, 2013: Improved airborne hot-wire measurements of ice water content in clouds. J. Atmos. Oceanic Technol., 30, 2121-2131, doi:10.1175/JTECH-D13-00007.1.

Kumar, S., A. Hazra, and B. N. Goswami (2013), Role of interaction between dynamics, thermodynamics and cloud microphysics on summer monsoon precipitating clouds over the Myanmar coast and the Western Ghats, Clim. Dyn., doi:10.1007/s00382-013- 1909 - 3.

Lemoine F.G.,, D. E. Smith, L. Kunz, R. Smith, E. C. Pavlis, N. K. Pavlis, S. M. Klosko, D. S. Chinn, M. H. Torrence, R. G. Williamson, C. M. Cox, K. E. Rachlin, Y. M Wang, S. C. Kenyon, R. Salman, R. Trimmer, R. H. Rapp, and R. S. Nerem (1997), The Development of the NASA GSFC and NIMA Joint Geopotential Model, Gravity, Geoid and Marine Geodesy, Vol. 117, 
International Association of Geodesy Symposia, J. Segawa, H. Fujimoto, and S. Okubo (editors), pp 461-469.

Lock, AP., Brown AR, Bush MR, Martin GM, Smith RNB (2000). A New Boundary Layer Mixing Scheme. Part I: Scheme Description and Single-Column Model Tests. Monthly Weather Review 128: 3187-3199, DOI:10.1175/1520-0493(2000)128<3187:ANBLMS>2.0.CO;2

Mace, G. G., R. Marchand, Q. Zhang, and G. Stephens (2007), Global hydrometeor occurrence as observed by CloudSat: Initial observations from summer 2006, Geophys. Res. Lett., 34, L09808, doi:10.1029/2006GL029017.

Mahakur, M., Prabhu, A., Sharma, A. K.,Rao, V. R., Senroy, S., Singh, Randhir and Goswami, B. N. (2013), A high resolution outgoing longwave radiation dataset from Kalpana-1 satellite during 2004-2012, Curr. Sci.,105(8), 1124-1133.

Maheshkumar R.S., Padmakumari B, Mahen Konwar, Morwal S.B., Deshpande C.G. (2018) Characterization of hydrometeors and precipitation over the Indian monsoon region using aircraft measurements Atmospheric Research 205 (2018) 147-154

Martin G. M., S. F. Milton, C. A. Senior, M. E. Brooks, S. Ineson, T. Reichler and J. Kim (2010) Analysis and Reduction of Systematic Errors through a Seamless Approach to Modeling Weather and Climate. Journal of Climate, 23: 5933-5957.

Menon A., A. G. Turner, G. M. Martin and C. MacLachlan (2018) Modelling the moistening of the free troposphere during the northwestward progression of Indian monsoon onset, Quarterly Journal of the Royal Meteorological Society, 144, 713: 1152-1168.

Misra, V., Bhardwaj, A. and Mishra, A. Clim Dyn (2018) Local onset and demise of the Indian summer monsoon 51: 1609. https://doi.org/10.1007/s00382-017-3924-2

Mitra, A. K., Momin, I. M., Rajagopal, E. N., Basu, S., Rajeevan, M. N., \& Krishnamurti, T. N. (2013). Gridded daily Indian monsoon rainfall for 14 seasons: Merged TRMM and IMD gauge 
analyzed values. Journal of Earth System Science, 122(5), 1173-1182. doi: 10.1007/s12040-0130338-3

Osborne, S. $\quad$ R., Abel, Steven J., Boutle, Ian A., Marenco, Franco $\quad$ (2004) Evolution of Stratocumulus Over Land: Comparison of Ground and Aircraft Observations with Numerical Weather Prediction Simulations, Boundary-Layer Meteorology, 153, 165, doi:10.1007/s10546014-9944-0

Parker D. J., P. Willetts, C. Birch, A. G. Turner, J. H. Marsham, C. M. Taylor, S. Kolusu and G. M. Martin (2016) The interaction of moist convection and mid-level dry air in the advance of the onset of the Indian monsoon Q. J. Roy. Meteor. Soc. 142: 2256-72

Peterson and Renfrew (2009) Aircraft-based observations of air-sea fluxes over Denmark Strait and the Irminger Sea during high wind speed conditions, doi: 10.1002/qj.355.

Prabha, T. V., A. Khain, R. S. Maheshkumar, G. Pandithurai, J. R. Kulkarni, M. Konwar, and B. N. Goswami (2011) Microphysics of premonsoon and monsoon clouds as seen from in situ measurements during CAIPEEX, J. Atmos. Sci., 68: 1882-1901

Rajeevan, M., Gadgil, S., and Bhate, J (2010), Active and break spells of the Indian Summer Monsoon, J. of Earth Sys. Sci. 119(3): 229-247.

Rakhi, R., Jayakumar, A., Sreevathsa, M. N. R., and Rajagopal, E. N. (2016) Implementation and up-gradation of NCUM in Bhaskara HPC NMRF/TR/03/ https://doi.org/10.13140/RG.2.1.4624.7923

Sandeep, A, A.K. Mitra, A.G. Turner, E.N. Rajagopal, K. Amar Jyothi, G. S. Bhat, and A. Jayakumar (2019) Inter-comparison of large-scale weather in the NCMRWF NWP model and FAAM aircraft measurements during the 2016 INCOMPASS field campaign, submitted to Quarterly Journal of the Royal Meteorological Society. 
Smith, R. N. B. (1990) A scheme for predicting layer clouds and their water content in a general circulation model. Quarterly Journal of the Royal Meteorological Society, 116: 435-460.

Stephens, G. L., et al. (2002), The CloudSat mission and the A-Train: A new dimension of space-based observations of clouds and precipitation, Bull. Am. Meteorol. Soc., 83(12) : 17711790.

Turner, A. G., G. S. Bhat et al. (2018) Interaction of Convective Organisation with Monsoon Precipitation, Atmosphere, Surface and Sea: the 2016 INCOMPASS field campaign in India. Quarterly Journal of the Royal Meteorological Society, accepted. DOI: 10.1002/qj.3633.

Vance, A. K., Abel, S. J., Cotton, R. J., and Wooley, A. M. (2015) Performance of WVSS-II hygrometers on the FAAM research aircraft, Atmos. Meas. Tech., 8: 1617-1625, doi:10.5194/amt-8-1617-2015.

Weverberg, K. V., Boutle, I. A., Morcrette, C. J., \& Newsom, R. K. (2016). Towards retrieving critical relative humidity from ground-based remote- sensing observations. Quarterly Journal of the Royal Meteorological Society, 142, 2867-2881. https://doi.org/10.1002/qj.2874

Wilson, D. R., A. C. Bushell, A. M. Kerr-Munslow, J. D. Price, and C. J. Morcrette (2008), PC2: A prognostic cloud fraction and condensation scheme. I: Scheme description, Q. J. R. Meteorol. Soc., 134, 2093-2107, doi:10.1002/qj.333.

Wood, N. et al. (2014), An inherently mass-conserving semi-implicit semi-Lagrangian discretization of the deep-atmosphere global non-hydrostatic equations, Q. J. R. M ete orol. Soc., 140(682), 1505-1520 

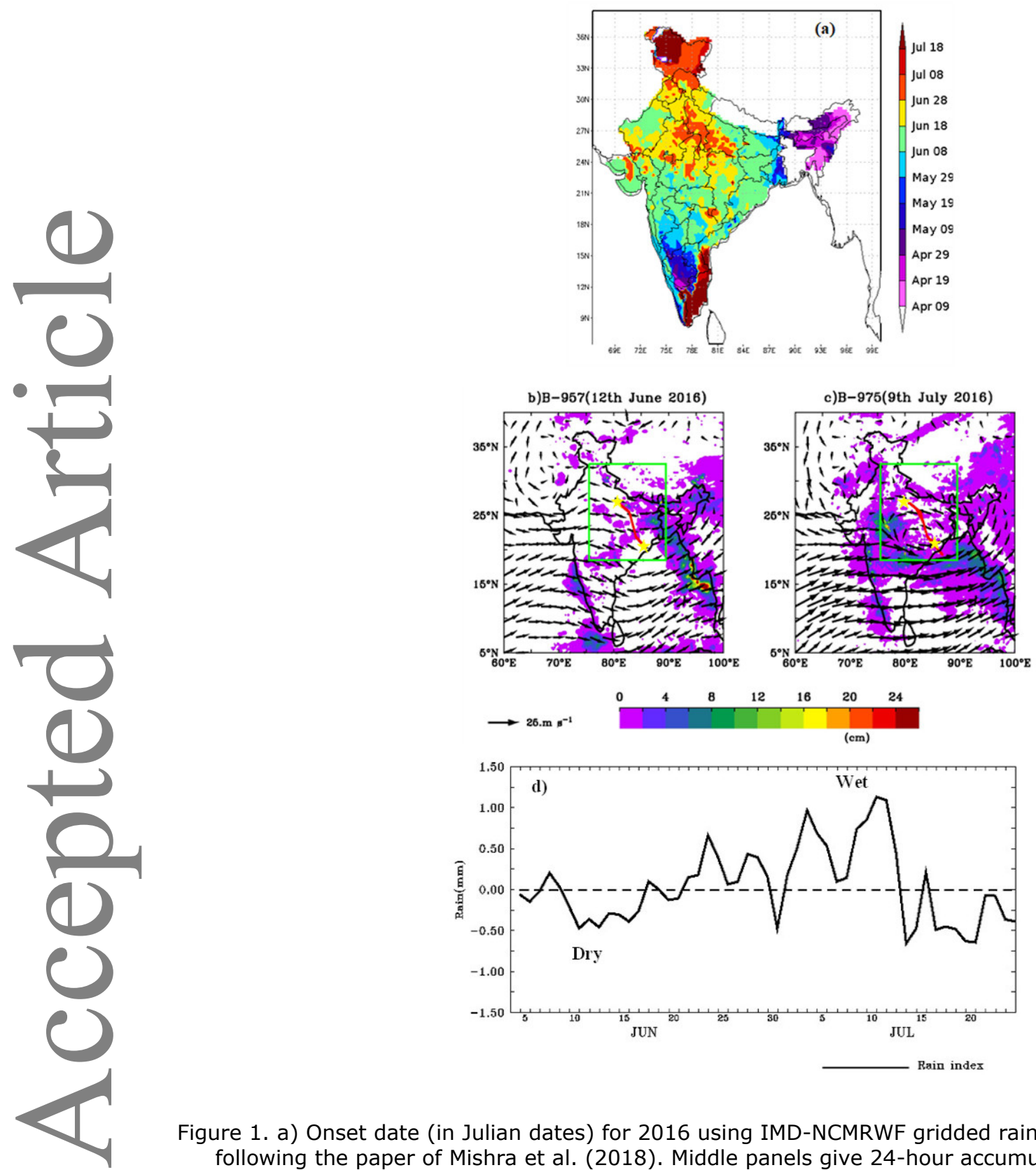

Figure 1. a) Onset date (in Julian dates) for 2016 using IMD-NCMRWF gridded rainfall data and methodology following the paper of Mishra et al. (2018). Middle panels give 24-hour accumulated observed rainfall (shaded) and 850-hPa wind (vector) for (b) 12June and (c) 9 July, 2016. FAAM flight tracks (B-957 and B-

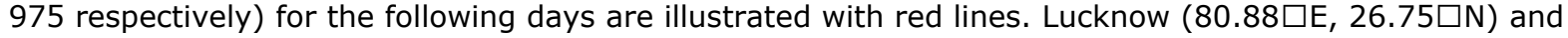
Bhubaneswar $(85.83 \square \mathrm{E}, 20.25 \square \mathrm{N}$ ) are plotted as stars. The model domain for the study period is displayed with green boxes. c) Monsoon wet-dry decomposition for the period June to July, 2016 monsoon using rainfall (black curve; Rajeevan et al. 2010) and the BT index (red curve; Jayakumar et al., 2017). 

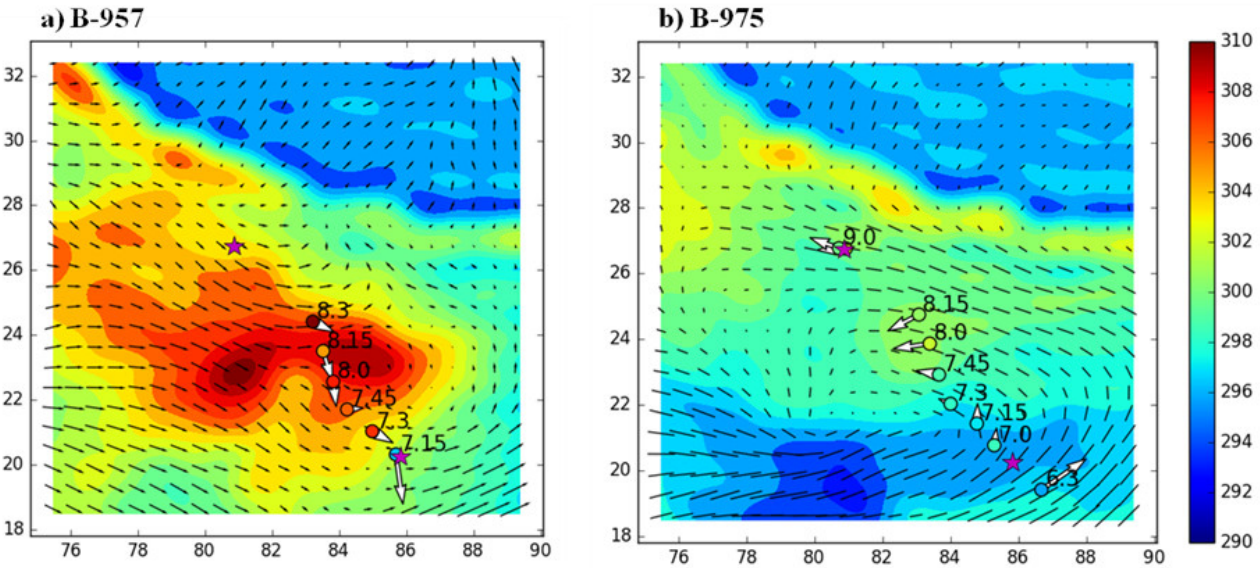

Figure 2. Air temperature (circle, K) and wind bars (m s-1) from the lower portion (200m < height < $2000 \mathrm{~m}$ ) of the flight tracks from a) B957 and b) B975 plotted against the background of $925-\mathrm{hPa}$ temperature (shaded) wind (vector) from ERA-Interim. The time of the aircraft data are indicated next to each circle and the reanalysis data are valid at 12 June 6UTC and 9 July 6UTC respectively. Lucknow $(80.88 \square \mathrm{E}, 26.75 \square \mathrm{N})$ and Bhubaneswar $(85.83 \square \mathrm{E}, 20.25 \square \mathrm{N})$ are plotted as stars. 

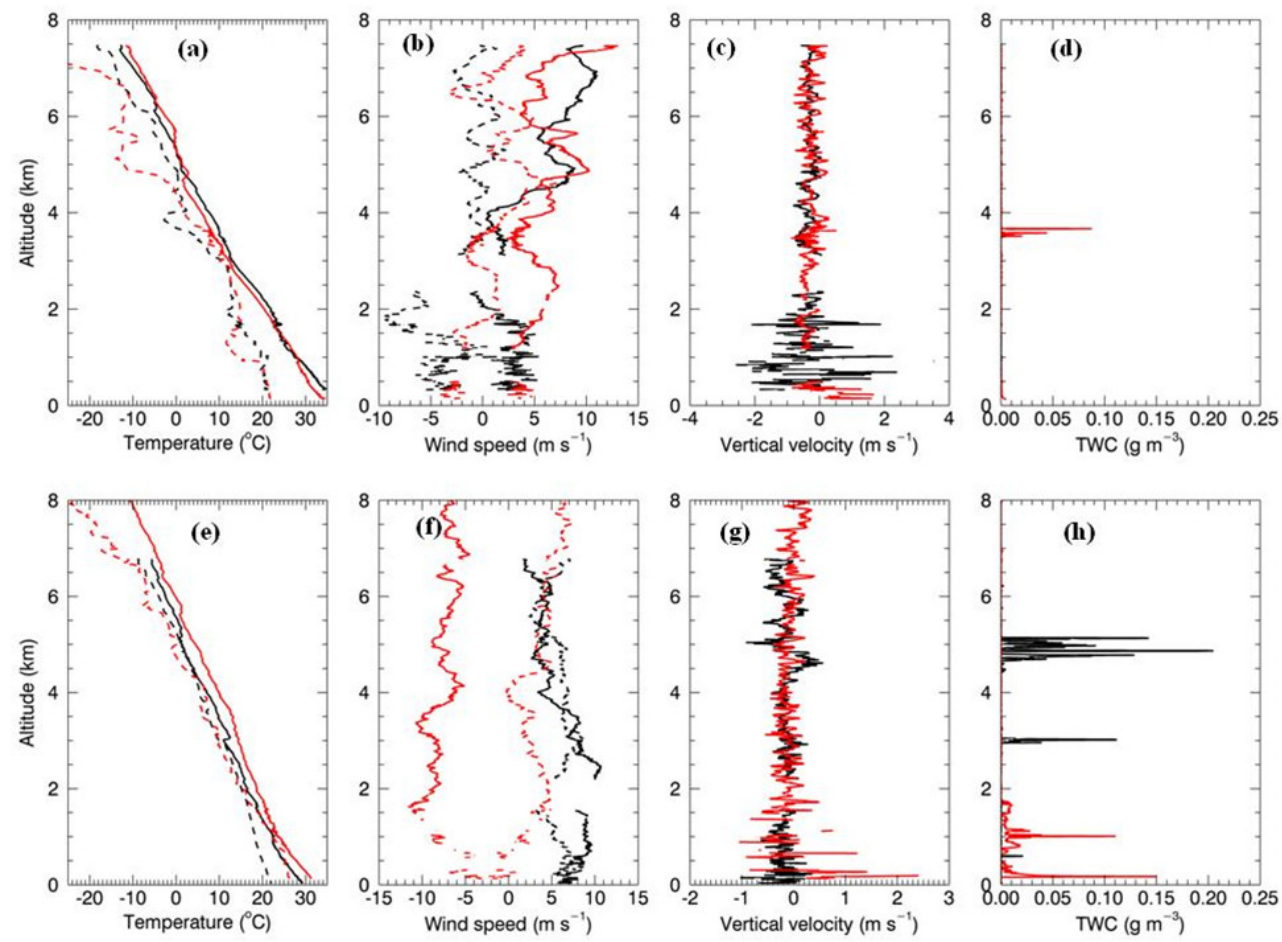

Figure 3. Profiles of (a) temperature (solid) and dew-point temperature (dashed) (left panel), (b) u (solid) and $v$ (dashed), (c) w wind (solid) and (d) Nevzorov TWC (solid) from B957. Profiles from B975 are plotted in similar fashion in the lower panels $(e-h)$. Data are screened out during aircraft turns, when the winds are no longer level. The initial profile in the northis red (Lucknow) and the profile before the low-level work in the south is black (Bhubaneswar). 

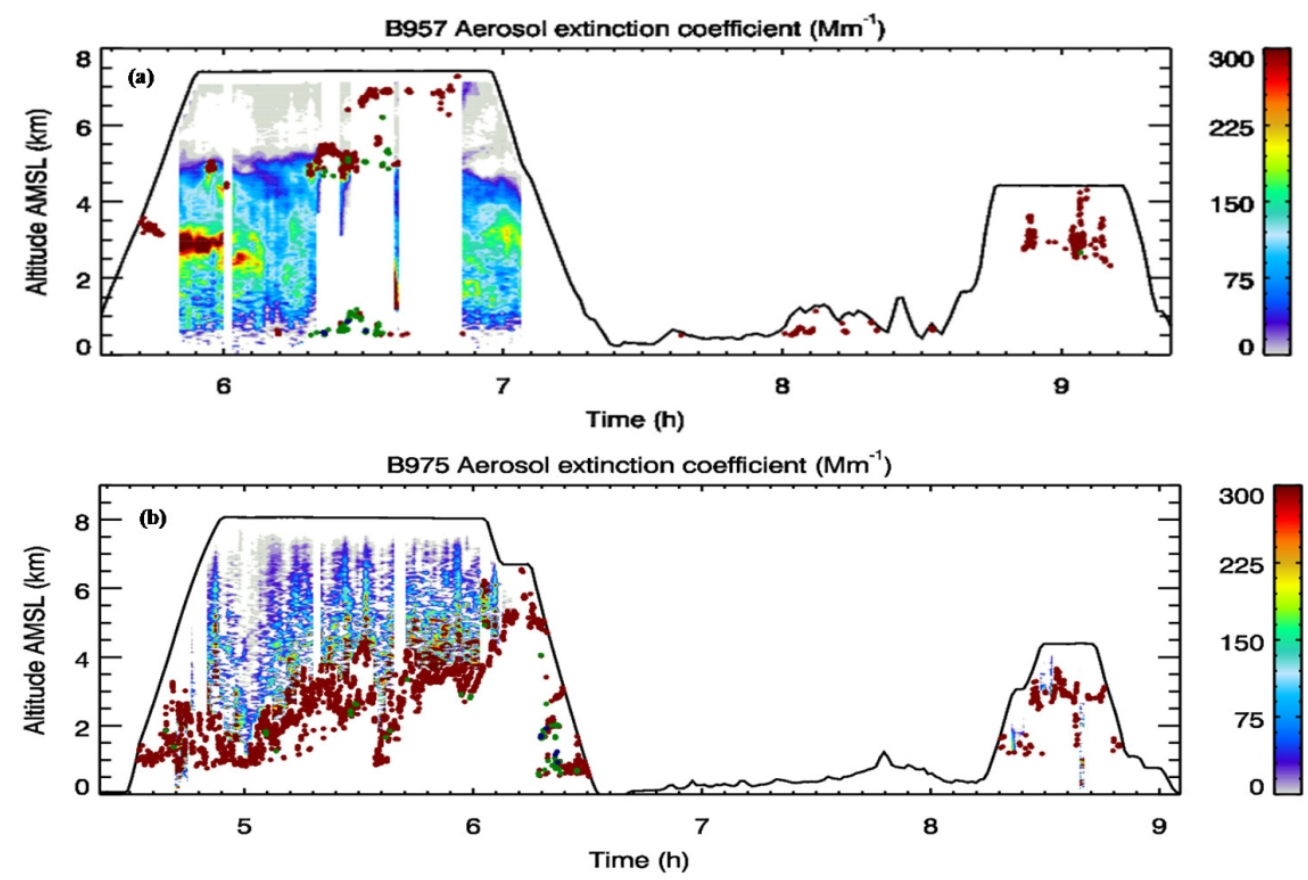

Figure 5. Aerosol extinction coefficient (shaded) and cloud-top heights from the downward-pointing lidar for flights (a) B957 and (b) B975. Red, green and blue circles indicate the 1st, 2nd and 3rd cloud-top heights detected below the aircraft. The 2 nd and 3rd cloud layers are only detected when the lidar signal is not attenuated by and cloud or aerosol layers above. 

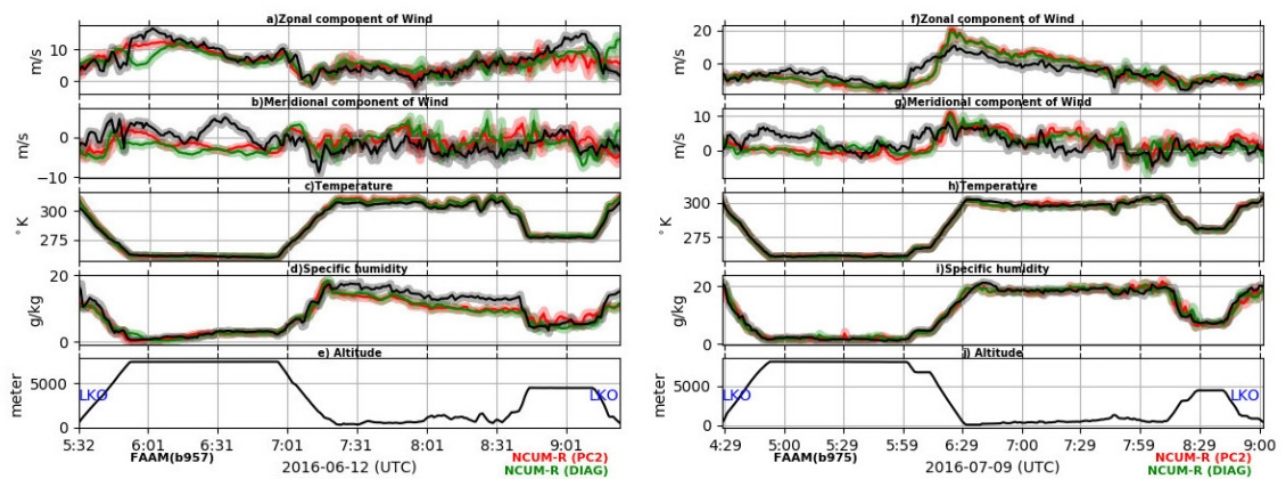

Figure 6. (a) zonal and (b) meridional wind components, (c) air temperature, (d) specific humidity for the corresponding altitude (e) from flight B957 (black curve). The corresponding model variables derived for the flight track from PC2 (red curve) and Diag (green curve) experiments are shown. The x-axis is illustrated as a period valid from the $t+24 \mathrm{hr}$ forecast of the model variables for day of flight. Right panels (f-j) are plotted for flight B975 in a similar fashion. The solid lines for PC2 (red) and Diag (green) are the mean profiles in a $13.5 \mathrm{~km} \times 13.5 \mathrm{~km}(9 \times 9$ grid $)$ box centred on the observational location, and the shading represents plus and minus one standard deviation. Black shading gives the standard deviation to represent the observational spread arising from $1 \mathrm{~Hz}$ measurement samples.

This article is protected by copyright. All rights reserved. 

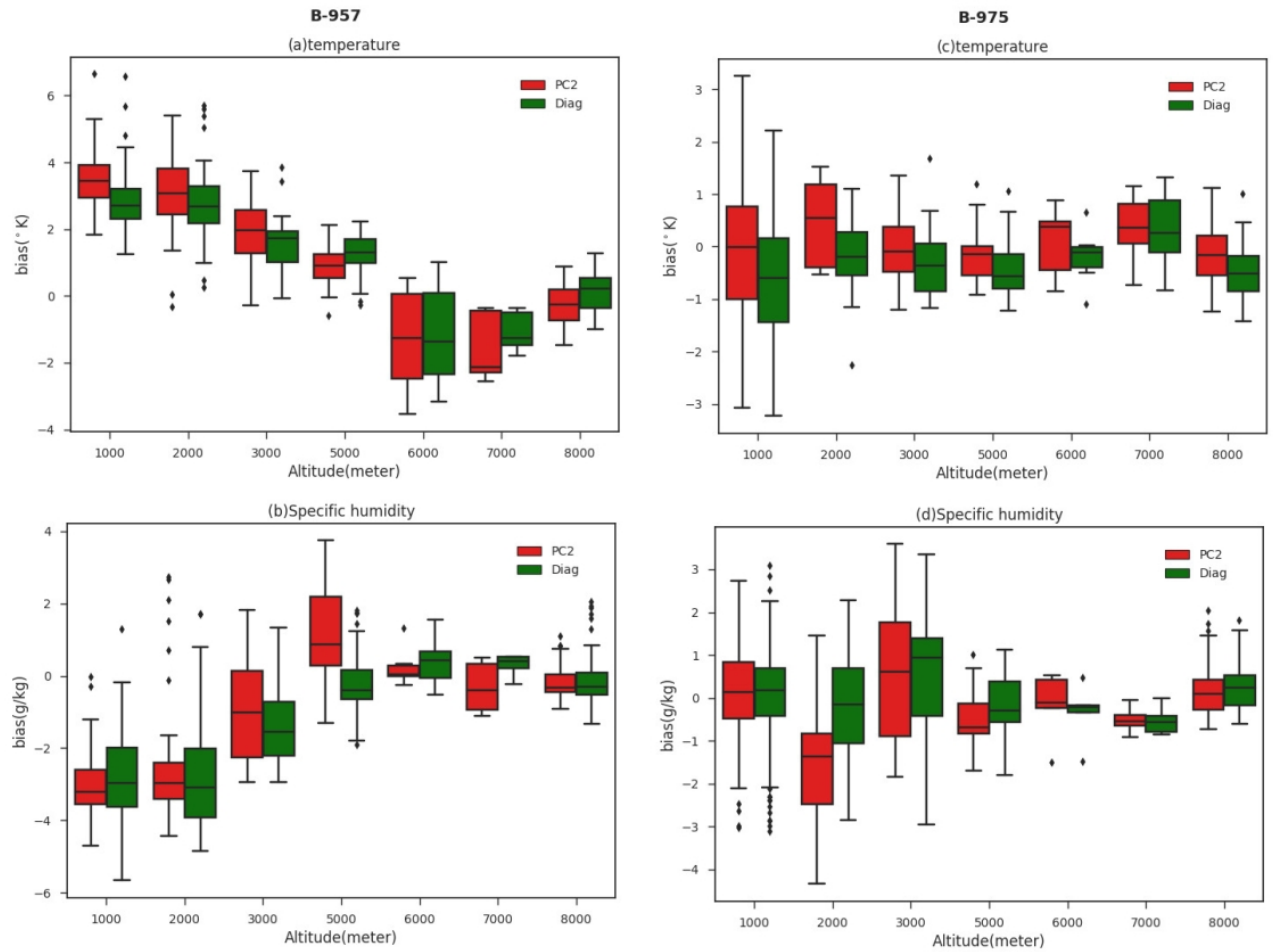

Figure 7. Box and whiskers plots of air temperature and specific humidity bias of PC2 (red) and Diag (green) from B957 (a, b) and B975 (c, d). Whisker indicates the spread of the bias, the boxes indicates a 25 75\% percentiles of the bias, black line in the box gives the median value and outlier is represented in the shape of black diamond. X-axis represents the different altitude bands (for example $1000 \mathrm{~m}$ corresponds to $0 \mathrm{~m}$ $<=$ height $<=1000 \mathrm{~m}$ ). 

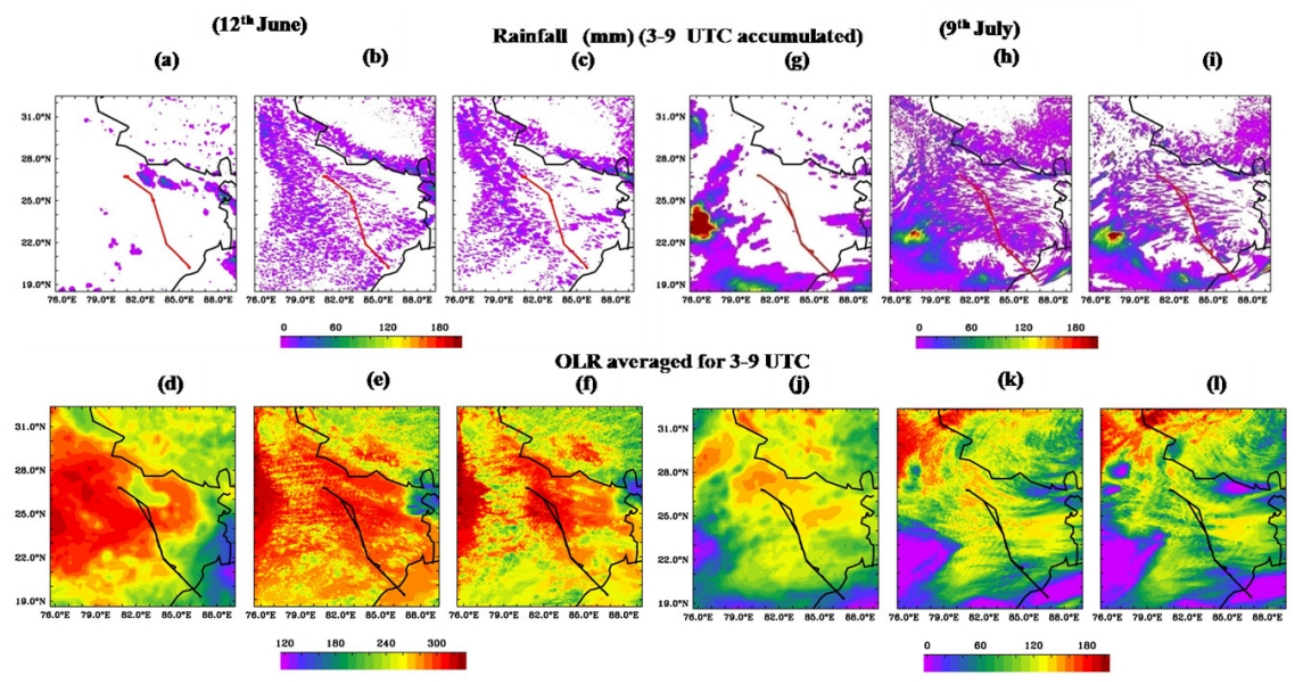

Figure 10. Rainfall accumulated (mm, shaded) for 3-9 UTC, 12 June from (a) GPM, (b) PC2 and (c) Diag experiments. OLR (Wm-2) averaged for 3-9 UTC, 12 June from (d) Kalpana VHRR, (e) PC2 and f) Diag experiments. Panels $(g-1)$ replicate (a-f) but for the 9 July. 

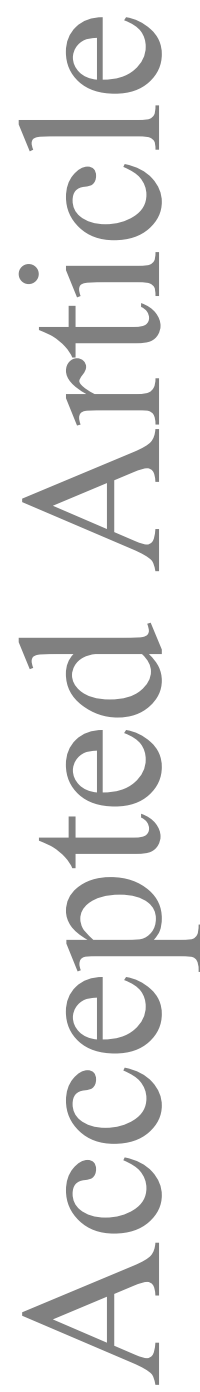

(a) TWC

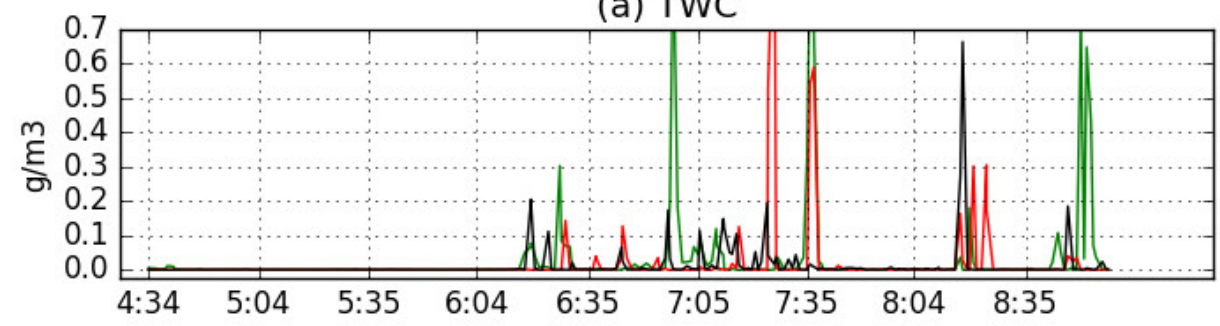

(b) LWC

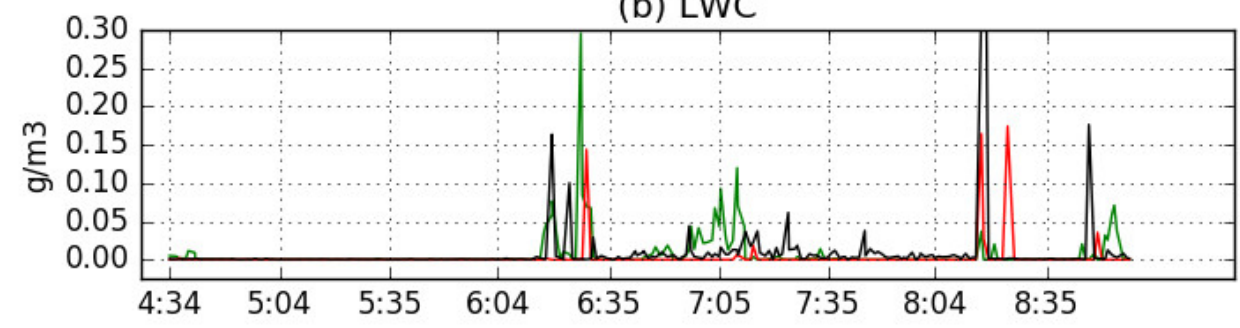

(c) Altitude

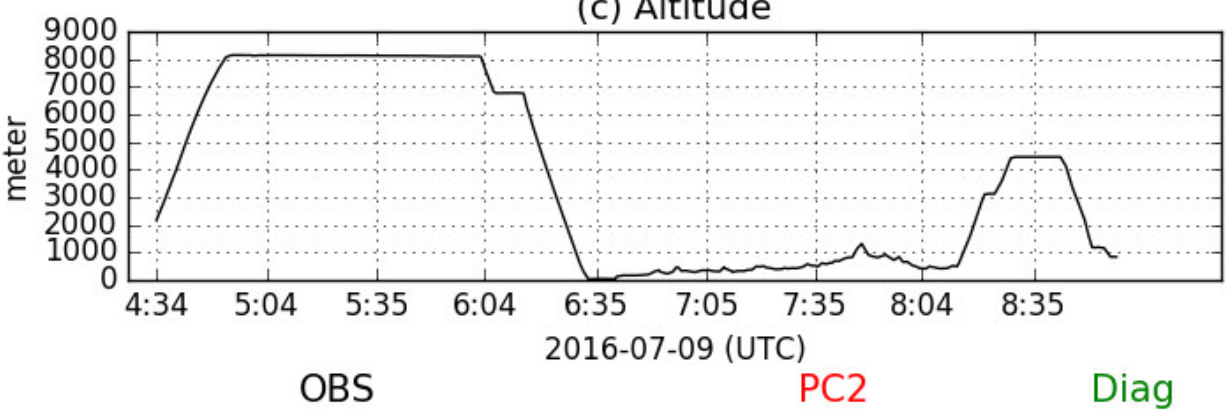

Figure 11. Cloud-top pressure from (a) MODIS (b) PC2 and (c) Diag experiments for the time valid for 5:30 UTC on 9 July 2016. 

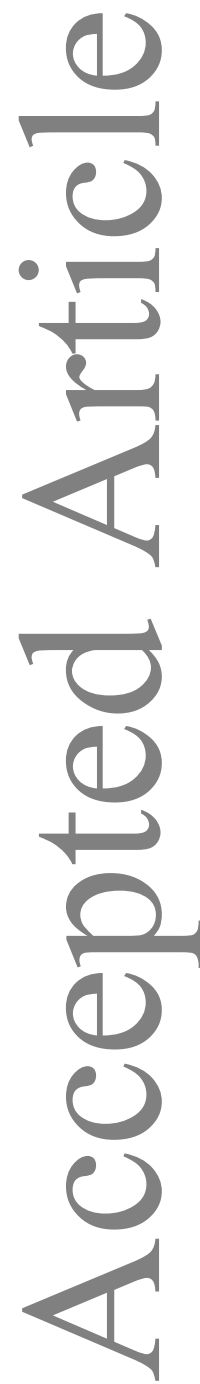
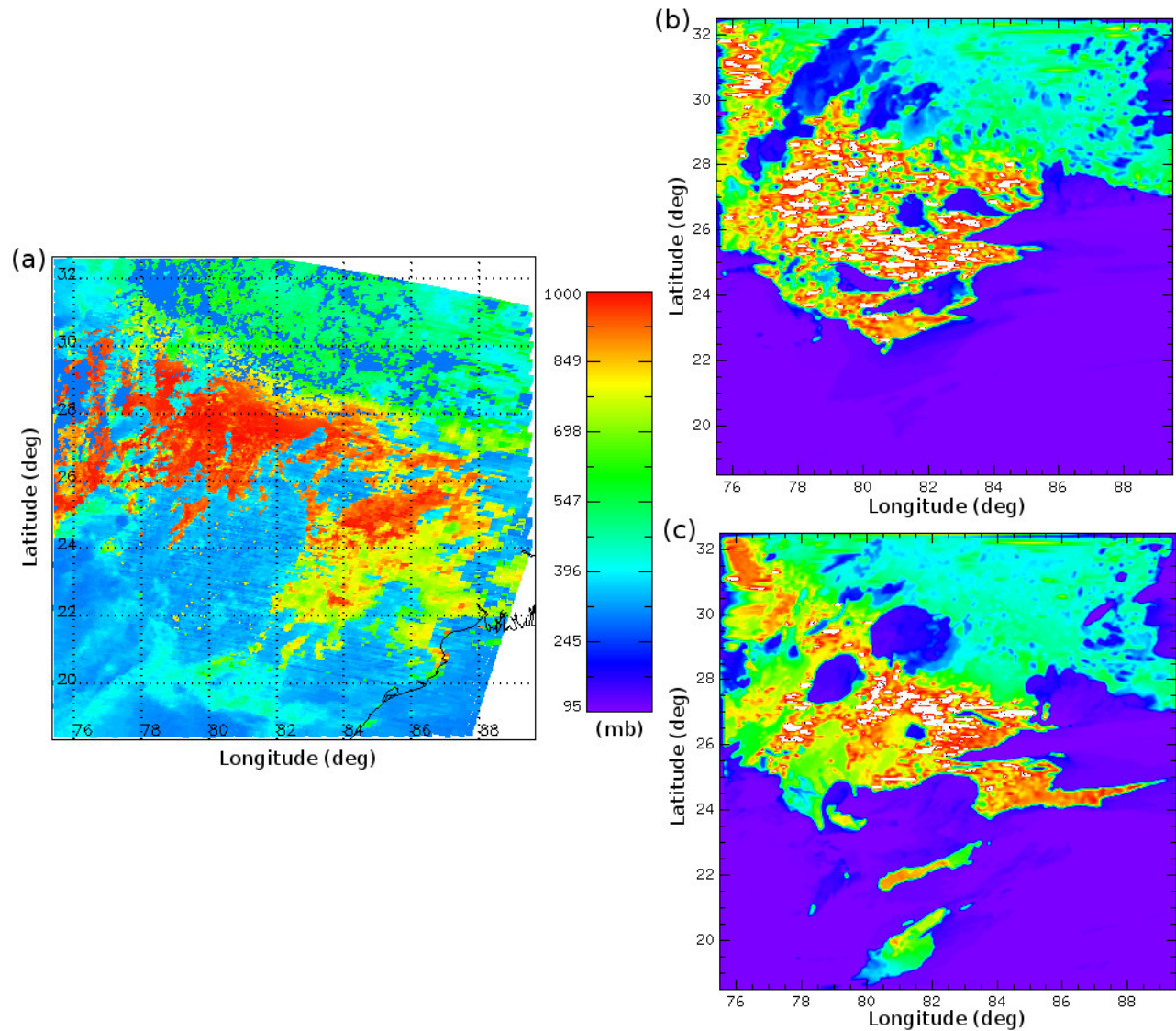

Figure 12. (a) Nevzorov TWC (combined rain water content and cloud-water content), (b) Nevzorov LWC along with the TWC and LWC from PC2 (red) and Diag (green) derived for flight B975.Time-height diagram corresponds to this flight track is shown in (c). 


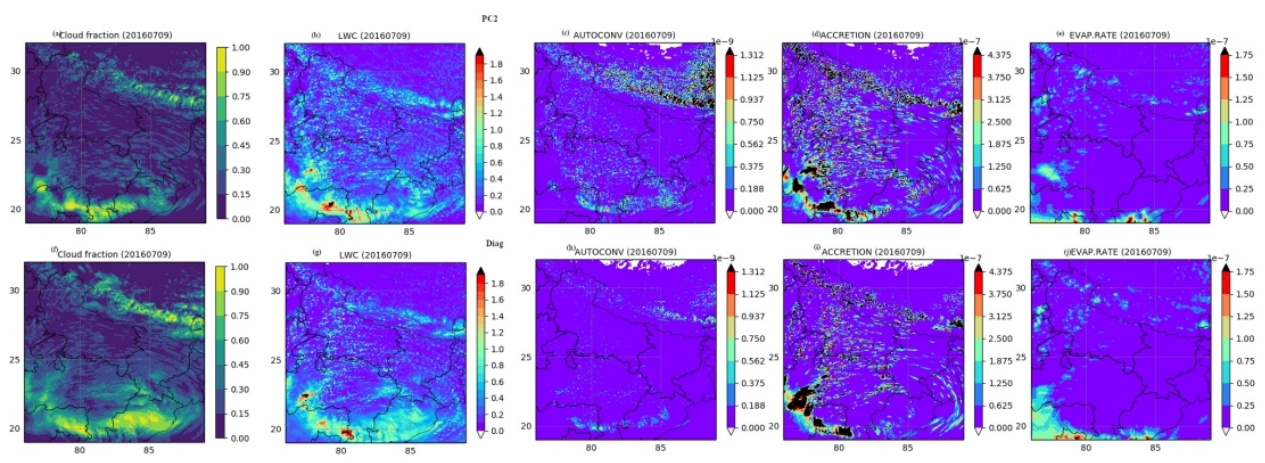

Figure 13. The horizontal distribution of vertically integrated (b) LWC and vertically averaged for the levels from $1000 \mathrm{~m}$ to $2500 \mathrm{~m}$ (a) cloud fraction (c) autoconversion, (d) accretion and (e) evaporation of rain $(\mathrm{kg} / \mathrm{kg} / \mathrm{s})$ averaged for 3-9 UTC, 9 July 2016 calculated from PC2; panels $(\mathrm{f}-\mathrm{j})$ shows the same for the Diag experiment. 


\begin{tabular}{|l|l|l|}
\hline \multirow{2}{*}{ Major science details } & \multicolumn{2}{|c|}{ Experiment } \\
\cline { 2 - 4 } & PC2 & Diag \\
\hline RHcrit & $\begin{array}{l}\text { Turbulent-kinetic- } \\
\text { energy-derived (TKE- } \\
\text { RHcrit) }\end{array}$ & Fixed RHcrit profile \\
\hline Large scale cloud scheme & "PC2" cloud scheme & $\begin{array}{l}\text { Diagnostic scheme } \\
\text { (Smith 1990) + ACF + } \\
\text { EACF }\end{array}$ \\
\hline
\end{tabular}

Table 1 Major difference between the PC2 and Diag experiments using NCUM-R (see main text for the details) 